\title{
PAISAGENS CULTURAIS MARÍTIMAS: DIÁLOGOS ATLÂNTICOS
}

\author{
Cristiane Eugênia Amarante ${ }^{i}$
}

Resumo: As Paisagens Culturais Marítimas são teoria e método ao mesmo tempo. Na tese de doutorado da autora deste artigo utilizouse uma abordagem etnográfica dentro desta vertente de análise para a compreensão de contextos arqueológicos marítimos na Praia do Francês, em Alagoas. Atualmente, ao se deparar com as Paisagens Culturais Marítimas da Ria de Aveiro, em Portugal, a autora mergulhou no universo de pescadores, construtores de barcos moliceiros e filhos de antigos apanhadores de moliço para compreender e analisar os contextos do outro lado do Atlântico. A metodologia utilizada, bem como os preceitos teóricos são os mesmos; no entanto, as pessoas, a geografia e o tempo trouxeram resultados bastante singulares em relação à experiência anterior. Embora a coleta de dados esteja em fase inicial, literalmente, já é possível redesenhar o mapa marítimo de porções da ria com as informações oferecidas pelos interlocutores. A seguir, com a análise dos dados se chegará a reflexões mais aprofundadas sobre estes espaços, trazendo luz a detalhes arqueológicos ainda obscuros desta região.

Palavras-Chave: Paisagens culturais marítimas, Arqueologia subaquática; Arqueologia marítima; Praia do francês; Ria de aveiro.

Abstract: Los Paisajes Culturales de los Mares son teoría y método al mismo tiempo. En la tesis doctoral del autor de este artículo, se utilizó un enfoque etnográfico dentro de este aspecto del análisis para comprender los contextos arqueológicos marítimos en Praia do Francês, en Alagoas. Ahora, cuando se encontró con los Paisajes Culturales Marítimos de la Ría de Aveiro, en Portugal, su obra actual, la autora inmersa en el universo de pescadores, constructores de barcos moliceiros e hijos de antiguos captadores de topos para entender y analizar los contextos al otro lado del Atlántico. La metodología utilizada, así como los preceptos teóricos son los mismos, sin embargo, las personas, la geografía y el tiempo trajeron resultados muy únicos en relación con la experiencia previa. Aunque la recopilación de datos se encuentra en las primeras etapas, es literalmente posible redibujar el mapa marítimo de secciones de la ría con lainformación ofrecida por los interlocutores. A continuación, con el análisis de los datos llegaremos a más reflexiones sobre estos espacios, llevando las luces a

iDoutora em Arqueologia pela Universidade Federal de Sergipe crisamarante.arqueo@gmail.com los detalles arqueológicos aún oscuros de esta región.

Palabras-claves: paisajes culturales marítimos, arqueología subacuática; arqueología marítima;praia do frances; ria de aveiro. 


\section{Introdução}

O artigo inicia-se com a apresentação das discussões teóricas dentro da vertente de análise Paisagens Culturais Marítimas. A princípio realiza-se um histórico inicial da utilização do termo pelo arqueólogo Christer Westerdahl na década de 1990. Posteriormente, já no século XXI, Brad Duncan propõe uma revisão teórica ao colocar em pé de igualdade análises econômicas, com avaliações de cunho político, social, etnográfico e simbólico do espaço. Este segundo autor tem influência da arqueóloga Bárbara Bender, que aponta subjetividade, multivocalidade e criatividade na elaboração mental sobre os espaços. Por fim, percebe-se como a autora deste artigo dialoga com os autores e segue uma linha etnográfica de análise conforme faz desde seu doutorado.

Na segunda parte do artigo faz-se uma explanação sobre como a autora deste texto vem aplicando as análises de Paisagens Culturais Marítimas, ao fazer uma distinção sobre como aconteceu no Brasil e como se realiza na Ria de Aveiro, já que houve adaptações na metodologia de entrevistas, ou seja, nas etapas iniciais do levantamento. A seguir apresentase o contexto geográfico e arqueológico da Ria de Aveiro e logo são descritos os relatos dos interlocutores, com os dados gerados pelas entrevistas com o devido levantamento das toponímias apontadas. Por fim, os traçados dos mapas físicos são delineados pelos mapas mentais, em que ideias aparentemente abstratas são materializadas em mapas a serem investigados pelos pesquisadores.

\section{Paisagens Culturais Marítimas: discussões teóricas}

O primeiro investigador a sistematizar as Paisagens Culturais Marítimas em termos de referenciais teóricos e metodologias foi Christer Westerdahl, na década de 1980 (Westerdahl, 1986, 1987a, 1989, 1992), a princípio com a preocupação de mapear as paisagens relacionadas a rotas e portos. Aos poucos a definição tornou-se cada vez mais sofisticada incluindo mais espaços marítimos como assentamentos, pesca, caça, navios, faróis e marcadores marítimos (Westerdahl, 1992).

Westerdahl (2001a, p. 338) defendeu que as atividades na costa, na porção marítima, são tão intensas quanto na terrestre, só que menos visíveis. E ainda, a documentação escrita ligada à 
esfera agrária é muito maior que a marítima, e esta escassez de fontes é refletida na produção acadêmica. Sendo assim, o termo Culturas Marítimas surgiu em oposição a Culturas Agrárias.

Com o passar do tempo, ele sistematizou os aspectos das Paisagens Culturais Marítimas (ibid., p. 339): Paisagens de Subsistência ou Paisagens Econômicas (que certamente inclui áreas de recursos terrestres); Paisagens de Recurso; Paisagens de Transporte - estuda caminhos e naufrágios; Paisagens Territoriais - de ataque e defesa; e Paisagens Cognitivas - paisagens da memória indicando nomes de lugares, paisagens ritualísticas e afins.

De início as classificações de Paisagens Culturais Marítimas tinham foco no fator econômico. Com o amadurecimento das investigações, houve o crescimento da percepção sobre as Paisagens Cognitivas (ibid., p. 339): “o fator cognitivo não está necessariamente ligado à prática econômica atual, ele vive na esfera ecológica"; e com isto o autor concluiu que "é míope a definição de que tudo é definido pelo econômico sempre". Ele inspirou-se em Marck Jasinski 1993 e percebeu que 'o imaterial era mais importante que o material', principalmente em relação aos nomes dos lugares, que são um fator cognitivo das paisagens do passado.

Esta percepção não foi só teórica, ela foi aplicada na prática e rendeu boas contribuições (ibid., p. 335 e 337). O método utilizado por Westerdahl (1987b, 2010) localizou entre 1700 e 1900 naufrágios no norte da Suécia. Numerosas indicações vieram de nomes sugestivos. Além disso, os nomes apontados por pessoas das comunidades locais auxiliam na reconstrução de paisagens submersas. Outra questão muito frequente na sua pesquisa são as resoluções sobre dois "problemas": Se "recursos do litoral" e "áreas estuarinas" podem ser considerados marítimos ou não. Sobre este assunto o autor define que "o ponto-chave são as pessoas marítimas".

As pessoas são o ponto central da teoria e metodologia desenvolvidas por Westerdahl (2011a, p. 342), que delineou 4 princípios da tradição oral sobre os sítios de paisagens culturais: 1. A tradição oral pode fornecer localizações exatas de locais e naufrágios. Isto é um princípio geográfico; 2. Pessoas têm realidades únicas. As informações genuínas vêm da tradição popular e não dos especialistas em história local. Talvez pobres, talvez sem estudos. Isto é um princípio social; 3. A maior parte das informações vêm das mulheres. Algumas caçadoras e pescadoras são mulheres. Isto é um princípio de gênero; 4. As conversas devem estar envolvidas em relacionamento pessoal, dentro de um estado de confidência mútua. Isto é um princípio pessoal. 
Outro ponto-chave e lúcido apontado por Westerdahl (2011a, p. 341) é o que ele chama de "perigo do presente". É preciso ter a nítida consciência de que o fator cognitivo das culturas é sempre uma interpretação mediada por negociações entre o entrevistador acadêmico urbano e o interlocutor simples marítimo. Ou seja, nem todas as nuances do universo pesquisado são captadas por quem entrevista, "principalmente quando envolve um sistema de 'superstições'".

Posteriormente, em 2006, Brad Duncan aprimora alguns pontos propostos por Christer Westerdahl. A sua maior crítica aos trabalhos desenvolvidos dentro das Paisagens Culturais Marítimas até então era o foco na economia (Duncan, 2006, p. 12). Segundo ele, "estes trabalhos usam o termo paisagens arqueológicas marítimas para investigações culturais que se confinam ao exame de práticas econômicas e, consequentemente, das suas assinaturas arqueológicas".

Duncan tem fortes influências da arqueóloga inglesa Barbara Bender (ibid., 2006, p. 12) Graças a este fator, ele passa a apresentar discussões não cronológicas e revisita o conceito de Paisagens Culturais, reconhecendo a diversidade de culturas nas paisagens e a descontinuidade entre as áreas terrestres e oceânicas. Ele elaborou o conceito de Paisagens Holísticas, em que descontrói dicotomias. Para este autor: Natural X Paisagens Culturais, Terra X Mar, Estático X Dinâmico - Paisagens Contínuas, Singular X Paisagens Multivocais são diferentes perspectivas para um mesmo espaço.

A partir dos pressupostos apresentados anteriormente, este autor elaborou uma nova sistematização dos aspetos das Paisagens Culturais Marítimas (Duncan, 2006, p. 21-35): Paisagem e Exclusão; Autoridade e Poder / Paisagens de Resistência; Evolução Tecnológica; Importância de Ações e Evento; Rotas; Percepções Sensoriais Alternativas e Conhecimento Ancestral; Ambientes em Transformação; Hierarquia Social; Gênero; Transportes e Paisagens; Rituais / Superstições / Simbolismo; e Memoriais / Monumentos.

Uma das questões abordadas por Duncan nesta classificação é o aspecto político-social. Muito do que ele elaborou já vinha sendo discutido por Westerdahl; no entanto, ao colocar as relações de poder nas sistematizações, há maior ênfase da análise destas características na paisagem. Este autor aponta que Westerdahl cunhou os termos "paisagens de poder", ao evidenciar "vestígios arqueológicos de toponímias possessivas (nomes autoritários)" e as "paisagens de resistência", que "são regiões que existem para resistir à autoridade" (ibid., p. 22). 
O foco de Duncan para as questões político-sociais também se observa em relação ao aspecto "hierarquia social" apresentado por ele dentro da sua sistematização (ibid., p. 29), em relação aos usos das conexões dos marinheiros "com comunidades marítimas particulares e expressões de determinadas profissões e diferenciações hierárquicas; algumas são diferentes das bases comunitárias terrestres".

Outro ponto forte da sistematização deste autor é o cuidado para a etnografia. Ele destaca a importância de conhecer o folclore local e os significados desses eventos nos estudos da paisagem, ao expor do aspeto "importância de ações e eventos". Ao tratar o aspecto "rotas", Duncan frisa que os marinheiros e pescadores usam uma "paisagem submersa" para a navegação e que essas marcas na paisagem "marcam um passado transferido de pai para filho" (ibid., p. 25). As rotas e marcos na paisagem compõem experiências de usos dos grupos dessas comunidades marítimas. Esses conhecimentos são parte de um sistema ancestral responsável pela elaboração de mapas mentais coletivos.

Muito pertinente a influência das teorias da arqueóloga e antropóloga inglesa Barbara Bender nesta reformulação dos aspectos de sistematização propostos por Duncan. Bender (2002, p. 103) desenvolve varias considerações sobre a paisagem; entre elas destaca-se que se trata de uma elaboração mental que envolve recordação, logo é criativa. Segundo a autora, a paisagem é um conceito negociável e labiríntico. E ainda, as recordações são sempre multivocais; portanto, existe uma subjetividade.

Sobre as recordações serem multivocais, esta autora explica que "as percepções do espaço mudam de acordo com gênero, idade, etnicidade, status social e orientação política. Há particularidades em diferentes escalas" (ibid., p. 107). Ou seja, a paisagem é materializada nas relações sociais que, conforme ela aponta, são dinâmicas. Bender também afirma que o papel do pesquisador é de "Arqueólogo Detetive" (ibid., p. 107), uma vez que é preciso "assumir que a interpretaçao do passado é problemática, pois sempre acontece no presente".

$\mathrm{Na}$ tese de doutoramento da autora deste artigo foi utilizado o termo paisagens etnográficas marítimas como conceito teórico, com base em Jean Yvie Blot (1999, p. 46). Este autor apresenta a necessidade de aproximação da Arqueologia Marítima com a Etnografia para "alargamento conceitual do debate". Blot aponta para a necessidade da disciplina, sair das explicações sobre os artefatos e tornar-se um diálogo cultural. 
Teoricamente, a autora deste artigo também apoiou-se na declaração de Quebec, sobre o "espírito do lugar". "Espírito do lugar existe, de uma forma ou de outra, em praticamente todas as culturas do mundo e é construído por seres humanos em resposta as suas necessidades sociais" (Carta de Quebec, 2008). Além deste documento, a autora também apoiou-se em Silva (2001, p. 89), que dentro da etnografia apontou para a força política de organizações de comunidades de mestres de ofício no Brasil Colonial; e também na pesquisadora Bárbara Bender (2002), que destaca a ação das pessoas com seu mundo no espaço, como sendo sócio-culturalizada e não natural. E sobre como estas relações pessoas espaço influenciam nas pesquisas de tradição arqueológica.

A seguir, um quadro que mostra as similaridades de diferenças nas duas perspectivas teóricas:

Tabela 1: Quadro comparativo entre Paisagens Culturais Marítimas e Paisagens Etnográficas Marítimas. Autoria: Cristiane Amarante

\begin{tabular}{|c|c|}
\hline Paisagens Culturais Marítimas & Paisagens Etnográficas Marítimas \\
\hline $\begin{array}{c}\text { Focada em subdivisões econômicas (subsistência, } \\
\text { recurso, transporte, território) }\end{array}$ & $\begin{array}{c}\text { Foco nos aspectos culturais } \\
\text { Aproximação com as Paisagens Cognitivas }{ }^{1} \text { e } \text { com a }^{\text {revisão de Duncan }}{ }^{2}\end{array}$ \\
\hline $\begin{array}{c}\text { Método pré-definido de coleta e sistematização } \\
\text { de dados }\end{array}$ & $\begin{array}{c}\text { Coleta de dados com base em temas pré- } \\
\text { estabelecidos com abertura para } \\
\text { complementações do interlocutor }\end{array}$ \\
\hline Foco no pesquisador & Equilíbrio pesquisador e interlocutor \\
\hline Macroáreas de estudo & Microáreas de estudo \\
\hline
\end{tabular}

As duas maiores diferenças entre as Paisagens Culturais Marítimas e as Paisagens Etnográficas Marítimas é que nesta segunda não há uma sistematização prévia das categorias de análise. Estas se definem após as análises de dados das entrevistas. Assim sendo, no caso da Praia do Francês em Alagoas, Brasil, os aspectos ficaram da seguinte forma: Tempo e Mudanças; Pesca; Navegação e Estruturas.

Outro ponto que diferencia as Paisagens Culturais Marítimas das Paisagens Etnográficas Marítimas é o tamanho das áreas de estudo. No caso da primeira, são grandes áreas e longo tempo de levantamento de dados, o que gera uma maior quantidade de informações a serem analisadas. Por este motivo, embora a autora deste texto traga a experiência do doutorado, com aspectos mais etnográficos, principalmente nas entrevistas, que são menos estruturadas,

\footnotetext{
${ }^{1} \mathrm{O}$ estudo das Paisagens Cognitivas é uma análise da vida social. Sempre existe o perigo do presente. O fator cognitivo das culturas e subculturas exige um modo alternativo de interpretação (Westerdahl, 2011b, p. 341).

2 Apesar da proximidade, Duncan propõe várias subdivisões nas Paisagens, postura que não foi adotada nesta pesquisa. Realizamos poucos agrupamentos e partimos das informações dos interlocutores para a caracterização dos blocos temáticos (ver anexo 2).

${ }^{3}$ Base em Estudos Culturais e de Recepção (ver item 1.5).
} 
ao final da experiência em Portugal, optaremos pelas Paisagens Culturais, por se adaptarem melhor à realidade atual, de maior área e mais tempo de pesquisa.

\section{Contextos da Ria de Aveiro, Portugal}

Em termos geomorfológicos, a Ria de Aveiro, segundo Maria Luisa Blot (1999, p. 56), pode ser interpretada como um Complexo Portuário. Sobre estes, ela explica que:

Entendemos por complexos portuários os grupos de unidades portuárias que, seja de menor importância, seja com um papel subsidiário, funcionaram como peças ativas de uma mesma realidade portuária global existente, ou no curso navegável de um rio, e num estuário, ou nos recortes de um espaço lagunar, ou numa ria, ou "mar interno", ou mesmo em abrigos costeiros operando em simultâneo, bem como alternadamente, num mesmo troço de costa.

Observamos que cada complexo portuário fluvial funciona graças à conjugação do papel determinado pelo terminus, ou seja, o ponto que oferecia condições de ancoradouro aos navios de maior calado, com a presença das embarcações menores que permitiam o transbordo e o transporte fluvial, quer até os portos da foz, varando em terra para o desembarque, quer até aos portos secundários, a montante, nos quais eram distribuídas as mercadorias.

A Ria de Aveiro é um dos maiores exemplos do que é explicado nos parágrafos acima- uma Ria, onde vários portos interiores e fluviais são ligados a um Porto maior, ou "terminus" com saída para o mar e ancoradouro para barcos maiores.

A Ria de Aveiro possui um conjunto de sítios de naufrágios, respeitável tanto em número de embarcações cadastradas, como nas datações atribuídas a elas, dado que testifica o dinamismo econômico deste complexo portuário no Período Moderno. Bettencourt (2009, p. 168 - 169) fez uma seleção de dados e obteve os seguintes resultados: Ria de Aveiro A, RAVA; Ria de Aveiro B, RAVB; Ria de Aveiro C, RAVC; Ria de Aveiro D, RAVD; Ria de Aveiro E, RAVE; Ria de Aveiro F, RAVF; e Ria de Aveiro G, RAVG. Todos encontrados entre 1973 e 2003, com datações entre 1280 - do RAVF e 1630 - datação mais tardia do RAVA4.

\footnotetext{
4 Há outros naufrágios mapeados na Ria de Aveiro. Estes, apontados neste parágrafo, são as embarcações descritas por Bettencourt (2009).
} 
Os sítios arqueológicos da Ria de Aveiro não se restringem aos naufrágios. Há assentamentos de diversas cronologias, desde a Pré-História "a presença do sítio Vale Videira 1, na Zona do Eixo/Eirol, em Aveiro, enquadrado em cronologias do Paleolítico Superior, nomeadamente no Gravettense" (Silva e Branco, 2017, p.68). O território, hoje submerso, constituía-se de uma plataforma propícia para a convivência de comunidades, porque a linha d’água era mais distante que a atual, o que o tornava, no passado longínquo, uma plataforma "com um bom domínio visual".

No âmbito do Projeto Empreitada de Transposição de Sedimentos para a otimização do Equilíbrio Hidrodinâmico na Ria de Aveiro, onde se desenvolvem essas pesquisas apontadas neste artigo, em 2019, mapearam-se os primeiros sítios submersos do Período Neolítico de Portugal, no Município de Ilhavo, onde se encontraram cerâmicas e artefatos líticos deste período.

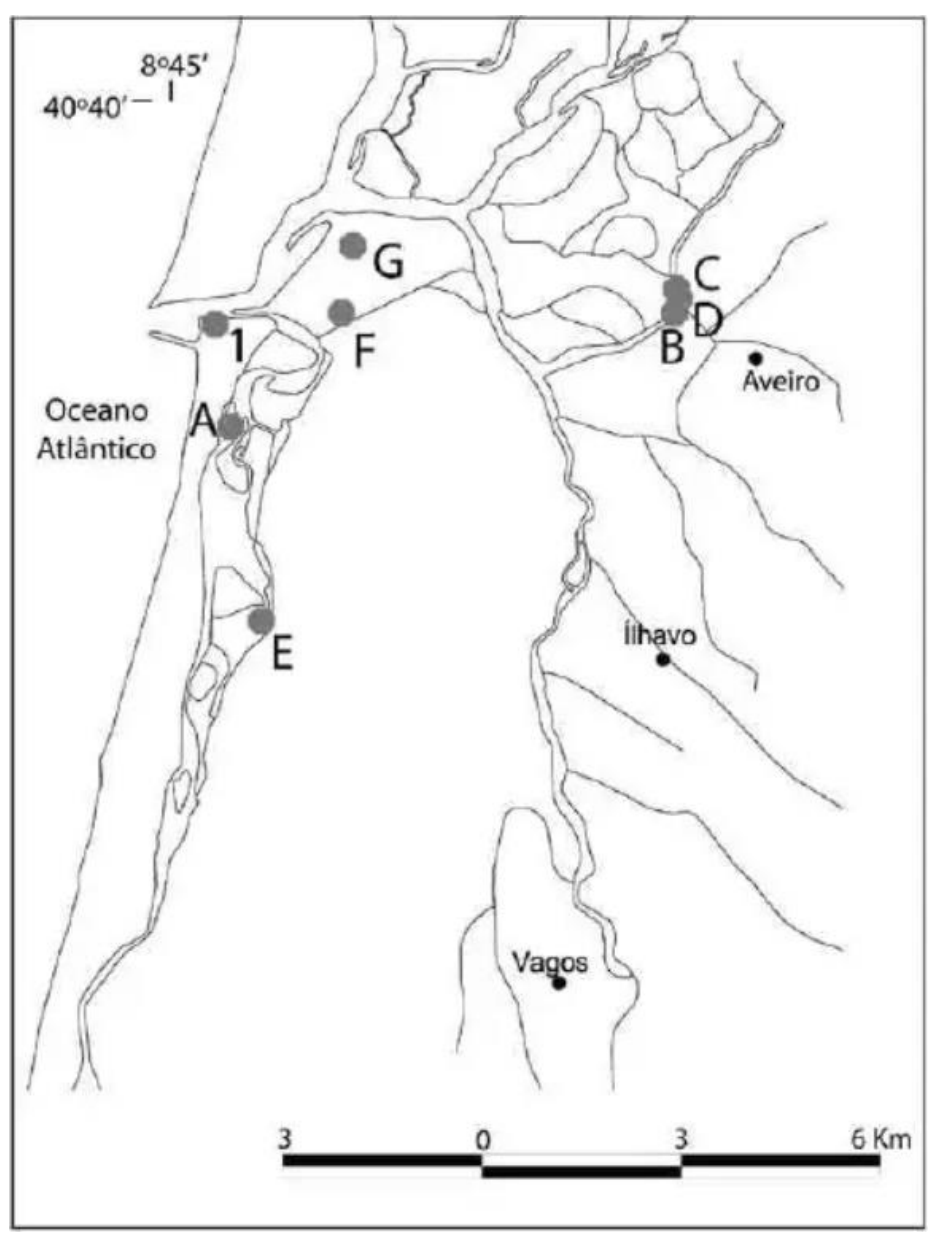

Figura 1: Localização da Ria de Aveiro e dos sítios arqueológicos subaquáticos mais importantes. Bettencourt, 2009, p. 168. 
No momento, as entrevistas realizadas estão somente na fase de levantamentos de dados. No entanto, em uma etapa posterior de análise, é preciso estar em atenção para o fato de que as toponímias podem revelar sítios de diferentes cronologias, não só do período histórico. A hipótese é plausível, tendo em vista que isto ocorreu em outras pesquisas anteriores a esta, que se utilizam da mesma metodologia.

\section{Os traçados dos mapas físicos delineados pelos mapas mentais}

No caso da Comunidade de Pescadores da Praia do Francês, em Alagoas, no Brasil, conversouse com os habitantes mais antigos do local. Havia um roteiro de perguntas pré-elaborado sem necessariamente haver a obrigação de se seguir a ordem: "a Praia do Francês no passado; a relação das pessoas com o mar; festas; divindades; comidas; barcos e construção; pesca; negativos de extração de rochas". Por fim, as respostas dos interlocutores foram transcritas e categorizadas por blocos temáticos, seguindo-se a analise à luz das leituras dos autores consultados.

Neste caso, a toponímia era importante, mas compreender a dinâmica da paisagem no passado era tão ou mais importante que os nomes das localidades. Para dar um exemplo disto, é importante lembrar que a quantidade de nomes dados aos currais deu as dimensões sobre quantos cais existiam na Praia do Francês, já que cada um deles tinha um curral de pesca associado. A observação do pescador também gerou a percepção de que mineração para cantaria e atividades de pesca conviviam no mesmo espaço. Além disso, a toponímia barreta e sua explicação fizeram perceber que cada um desses cais possuía saída independente para o mar, sem necessariamente ter que dar a volta no canal para acessá-lo.

Na Ria de Aveiro a metodologia é diferente, uma vez que as entrevistas não são gravadas e não há um roteiro prévio. $\mathrm{O}$ objetivo principal das conversas já é voltado para reconhecer as toponímias e as devidas localizações. Após a conversa, em que a pesquisadora anota os pontos principais, na sequência se redige um resumo do relato, em que esses nomes e explicações são devidamente registrados. O passo seguinte é um diálogo com um arqueólogo, que transfere as informações fornecidas para o mapa, em que aos poucos começamos a perceber esta forma de guiar-se no espaço a partir do que está embaixo d'água, como bem explicam Duncan e Westerdahl. 
Esta pesquisa encontra-se na fase de levantamento de dados. Seguem as transcrições das entrevistas realizadas até então. Os nomes dos entrevistados foram trocados pela palavra interlocutor, tendo um número, para preservar a identidade do colaborador. Como os textos são resumidos pela autora deste artigo, eles seguem tais quais foram registados.

Conversa com interlocutor 1: filho de apanhador de moliços na Ria de Aveiro, realizado em 16 e 17 de julho de 2019

Ele contou que o pai e o avô eram panhadores de moliços na Ria de Aveiro; explicou que antes da construção da ponte da Varela (década de 1950), a Torreira era chamada pelos moradores de 'A llha', porque só dava para chegar lá de barco. Isso nos chamou a atenção. Esse nome pode ser de 100 anos ou de mais tempo, tendo em vista que a Torreira não é na realidade uma ilha atualmente.

Ele informou também que existem dois naufrágios na Torreira, do lado da Praia. Um foi visto pela população na década de 1920, bem perto da Torreira ; ou outro um pouco mais ao norte. E entre as décadas de 1930 e 1950, ambos teriam sido descobertos pelo próprio mar e o recuo das areias.

Também informou que existia um barco naufragado do lado oposto de onde estamos, a uns 50 ou 100 m. O nome da embarcação era Rainha Santa. Este barco serviu de restaurante por um tempo e depois sofreu um incêndio. Essa história é bastante conhecida pelos locais.

O interlocutor 1 gostava de explicar o significado dos nomes dos lugares (toponímia). Segundo ele, sua professora, Rosa Branca, da escola primária contava histórias e explicava. Ovar - lugar onde os peixes botam as ovas. Murtosa - o nome inicial seria 'mortosa', de morte, por conta das disputas entre pescadores. Cais da Marinha - lugar onde tinham as marinhas de sal. Arribação - lugar onde os moliceiros arribavam (atracavam?).

Conversamos com ele sobre a Torreira inicialmente ser uma barra. Ele ficou pensando se o Furadouro era igual, como outra barra. Foi uma hipótese ali de momento. Também explicou que na tradicional festa de San Paio, em setembro, há regatas de moliceiros e bateiras. Todos eles com vela, como era no passado. $\mathrm{E}$ a regata de bateiras acontece com o uso de remos.

Outra informação é que no Cais Ribeira de Pardelas teria um estaleiro de moliceiros, próximo a uma escola (É preciso conferir se a localização é essa mesma). Também ouvimos sobre os três 
tipos de barcos na Ria de Aveiro: Bateira - o menor, de 5 a 7 m; Mercantel - o médio, de 10 a $12 \mathrm{~m}$; Moliceiro - o maior, com aproximadamente $15 \mathrm{~m}$.

Por fim, conhecemos também a receita tradicional das enguias fritas. Primeiro se fritava o porco no tacho; a gordura que ficava era utilizada para fritá-las . Hoje, um pescador de enguias consegue apanhar em torno de três quilos por semana (muito menos que no passado) e na Murtosa existem criadouros para abastecer os restaurantes, porque o que existe na Ria não é suficiente.

Interlocutor 2: pescador que possui um barco moliceiro utilizado para turismo em Aveiro, entrevistado no Cais do Bico em XX de setembro de 2019.

O interlocutor 2 é dono do Moliceiro Dos Netos e da Bateira das Netas. Ele mudou-se para a região do Bico quando tinha 9 anos. Hoje tem por volta de 80 anos; chegou a morar períodos em outros países, Alemanha e Holanda, mas retornou para o mesmo local. Ele diz ser um dos moradores mais antigos, junto com outro senhor. Contou que o Cais do Bico tinha um estaleiro que chegou a construir barcos de Bacalhaus. Em 1945 foi às águas o Maria das Flores, com destino a Groelândia.

Ele relatou que a dragagem do Porto de São Jacinto, de 1945, mudou muito a dinâmica da Ria, aumentando a correnteza de $10 \mathrm{~km} / \mathrm{h}$ para $2.000 \mathrm{~km} / \mathrm{h}$. Sobre essas modificações na paisagem, ele destacou a região do Gramatal, que era seca e hoje chega a ter $2 \mathrm{~m}$ de profundidade.

Seu pai morreu em um acidente de barco, aos 42 anos, em 1947, na Ria. Segundo ele, a tragédia matou mais de 100 pessoas.

O interlocutor 2 ficou por um tempo trabalhando com moliceiros em Aveiro e não vê muito sentido no turismo ser realizado na região dos canais dentro da cidade. Sobre isso ele comenta: "São canais da Ria, e não a Ria". Diz também que algumas marinas de sal, que deixaram de funcionar há 40 anos, foram transformadas em locais de banho de argila. Ele se preocupa com a quantidade de mercúrio e poluição nas águas da Ria e vê a atividade com incredulidade.

No momento em que conversamos, ele estava preparando a bateira e o moliceiro para a festa de San Paio na Torreira. Nas corridas da festa os barcos navegam a velas, como tradicionalmente acontecia na época da coleta dos moliços. Ele tirou o motor da bateira e limpou as duas embarcações deixando tudo organizado para o evento. Ele contou que no dia 
seguinte levaria as velas para a embarcação, mas iria colocá-las só quando chegasse à Torreira. Em suas palavras "No Bico não dá jeito", é estreito e por causa do vento tem que ser colocada em um canal mais largo.

Outro assunto que ele comentou foi sobre as dragagens anteriores, que depositaram sedimentos na Zona do Hotel da Torreira, sem estacarias e, com o tempo, as areias retornaram a assorear o canal.

Interlocutor 3: pescador e construtor de mercantéis e barcos moliceiros. Entrevista realizada em 2019.

Primeiramente, encontramos o senhor no período da manhã, na porta de sua casa. Fomos ao Cais Ribeira da Aldeia e um senhor nos levou até ele, que vive nas cercanias. Ele nos informou que estaria à tarde a trabalhar na construção de um mercantel, em um estaleiro privado próximo a sua moradia. Combinamos de voltar às 15 horas para fazer fotos do barco no estaleiro e conversarmos com ele.

Quando voltamos à tarde, o senhor estava no estaleiro e nos recebeu juntamente com sua esposa. A princípio havia um visitante a tirar fotos, que logo foi-se. Começamos a conversar com ele sobre a construção do Mercantel. Ele explicou sobre as madeiras e mostrou o pau de pontos. Os construtores dedicam-se a estas explicações. Primeiro, porque é seu ofício e gostam de falar do assunto; segundo, porque toda a gente que os procura vai com interesse na construção. Neste caso, ouvir neste primeiro momento foi importante para gerar a conexão entrevistador e entrevistado.

Ele nos apresentou fotos dos pinheiros utilizados para a construção do barco que tinha no seu telemóvel, que, segundo ele, vem do Sul de Portugal. Em dado momento ele disse que foi pescador e que enquanto jovem buscava por moliços. No início da conversa o foco foi a arquitetura naval. Depois, partimos para as perguntas sobre a percepções dos lugares de referência e caminhos aquáticos realizados por ele e por outros pescadores.

Ele começou dizendo que os locais e caminhos já não são mais os mesmos. Há 50 anos, quando mudou-se a Barra, toda a dinâmica da Ria modificou-se (percebemos que os pescadores com quem conversamos sempre atribuem o assoreamento a este evento). A Ria, segundo ele, tinha uma variação de 20 a $40 \mathrm{~cm}$ no entre marés (entre as baixas e as altas) e que hoje essa variação chega aos $4 \mathrm{~m}$. 
Voltamos à discussão para o passado, pontos de referência e caminhos. E disse que a Ria tinha muitos pontos bons para pescar e falou sobre a "Casa da Senhora". Não conseguimos perceber onde se localizava. Hoje, os locais de pesca são possíveis de serem visitados somente na maré alta e ele navega só no verão. Disse que nos levaria a estes pontos, quando chegada a época.

Saudosamente disse também que existem locais de pesca do passado que hoje passam o tempo todo em seco. Uma informação bastante interessante foi a respeito do estaleiro do Cais da Ribeira do Nacinho. O interlocutor 3 e sua esposa disseram que em finais do século XIX foi construído ali uma embarcação de grandes proporções. Eles marcam o tempo desta construção pela idade das pessoas de mais idade da região. Dizem também que na ocasião houve uma dragagem, com o objetivo de abrir uma "Cale" (eles chamam assim) até a Barra. Eles atribuem a profundidade de $8 \mathrm{~m}$ da "Cale" principal a este período, mas dizem que a "Cale" que ligava o cais à Cale maior já não existe mais. Marcamos de voltar para continuar a conversa.

Voltamos para uma segunda conversa em que percebemos os locais marcados como bons para pesca, bem como os caminhos de navegação. As localizações apontadas foram transferidas para um mapa a posteriori.

Segue relato etnográfico realizado com o interlocutor 4, no dia 12 de fevereiro de 2020, no âmbito do empreendimento.

O senhor entrevistado é pescador; realiza passeios com barcos moliceiros e vem de uma família com tradição de pesca e apanha dos moliços. Então, apesar de jovem, 35 anos, conhece parte das toponímias utilizadas por seu pai e avô. A entrevista foi realizada com apoio de um mapa que corresponde à área onde se encontra a parte Norte do empreendimento, que vai da Murtosa a Ovar.

Percebemos na entrevista com este interlocutor que ele ofereceu informações de locais próximos onde está acostumado a pescar. Outro detalhe interessante é que as informações começaram a partir do ponto onde ele se encontrava na Ria de Aveiro naquele momento, no Canal da Murtosa. Acima da Região da Murtosa, até chegar no Canal entre a Bestida e a Torreira, há uma zona que os pescadores dão o nome de Lagoa.

Ele iniciou a narrativa pelos locais próximos já indicados no mapa: Ilha da Gaga, Gramatal e llha da Testada. Nesta última ele apontou um ponto ao qual chamou Pinheira e uma região que 
indicou como sendo a Praia da Senhora. Em seguida, ateve-se aos cursos d'água. A Carreira de Aveiro é chamada Carreira Velha. Mais ao sul, à volta da Ilha da Pedra (já indicada), passa um curso d'água chamado A Veia e outro menor chamado Veia da Pedra. Ao sul da llha da Pedra, ele apontou 3 pontos: Poço Bulhões, Pata e Marinha do Pata. Próximo a esta zona, mais ao leste, na Ilha do Parrachil (já indicada), há uma zona chamada Garanhão. No Rio Novo, mais ao sul, há um ponto chamado Os Cães.

Ao todo, este interlocutor indicou 11 sítios, conforme se observa no mapa: 01. Lagoa; 02. Pinheira; 03. Praia da Senhora; 04. Carreira Velha; 05. A Veia; 06. Veia de Pedra; 07. Poço Bulhões; 08. Pata; 09. Marinha do Pata; 10. Garanhão e 11. Os cães.

Os resultados das duas pesquisas são muito diferentes, conforme se observa no mapa. Isto se dá não só a diferenças de localização das pesquisas, mas, sobretudo, porque o objetivo e as metodologias se diferenciaram.

\section{Considerações finais}

A teoria e metodologia das Paisagens Culturais Marítimas foram aplicadas nos dois ambientes, ou seja, na Praia do Francês no Brasil e na Ria de Aveiro em Portugal. No entanto, devido às características de cada projeto, a metodologia sofreu adaptações e os resultados deram-se de maneira diferente.

No Brasil, as entrevistas permitiram que a pesquisadora tivesse melhor percepção dos espaços do passado por meio da interlocução com pessoas do presente. A navegabilidade, a pesca e a extenção da área de mineração à beira mar foram identificadas a partir do olhar dos locais.

$\mathrm{Na}$ Ria de Aveiro, as entrevistas dão-se no sentido de reconhecer toponímias e mapeá-las. Aos poucos, a geografia submersa local recebe os nomes após os levantamentos feitos com os interlocutores. O trabalho está em fase inicial, mas já permite levantar hipóteses sobre a ocupação deste espaço no passado em diferentes temporalidades.

Os trabalhos de Paisagens Culturais Marítimas exigem tempo: as conversas com interlocutores, análises dos dados e novas entrevistas que acrescentam dados às versões anteriores são partes de processos que podem levar meses e até anos. Cada indivíduo tem um olhar para seu próprio espaço de acordo com sua origem e interação com ele. Cabe a quem realiza a pesquisa 
perceber essas lentes próprias de cada entrevistado, para então construir análises mais sólidas a respeito das paisagens.

\section{Referência}

AMARANTE, C. Arqueologia Marítima na Praia do Francês. Tese Doutorado em Arqueologia. Universidade Federal de Sergipe. Laranjeiras, 2019.

BENDER, B. \& EDMONDS, M. Stonehenge: whose past? What past? Tourism Management. Volume 13. Numero 4. 1992. p. 355-357.

BETTENCOURT, J. Arqueologia marítima da Ria de Aveiro: uma revisão dos dados disponíveis. In: GARRIDO, Álvaro. Otávio Lixa Filgueiras: Arquitecto de Culturas Marítimas. Lisboa, Âncora Editora/Museu Marítimo de Ílhavo, 2009. p. 165 - 188.

BLOT, J. Y. O mar de Keith Muckelroy: o papel da teoria na arqueologia do mundo náutico. AlMadan, Almada, Centro de Arqueologia, série 2, n.8, p. 41-55, out.1999. 3.

BLOT, M. L. Dinâmica litoral, navegação e modelos de portos (fundamentação teórica).

DIARIO DE ILHAVO. Descoberto primeiro sítio subaquático marítimo de llhavo. Agência Lusa. 17 set. 2019.

DIEGUES, A. C. Pescadores, camponeses, trabalhadores do mar. São Paulo: Ática, 1983.

DUNCAN, B. G. The maritime archaeology and maritime cultural landscapes of Queenscliff: a nineteenth century Australian coast community. Tese de Doutorado. James Cook University, North Queensland, 2006.

ICOMOS. Declaração de Québec: sobre a preservação do "Spiritu loci": assumido em Québec, Canadá, em 4 de outubro de 2008. Paris: Icomos, 2008.

SILVA, A. R. e BRANCO, Jorge. A Arqueologia no Município de Ilhavo. In: GARRIDO, et all. Ilhavo: Terra Milenar. Câmara Municipal de Ilhavo. Ilhavo, 2017

SILVA, L. G. A faina, a festa e o rito: uma etnografia histórica sobre as gentes do mar (séculos XVII ao XIX). Campinas: Papirus, 2001.

WESTERDAHL, C. Conclusion: The maritime Cultural Lanscape Revisited. FORD, Ben (ed). The Archaeology of Maritime Landscapes. Springer. 2011b.

WESTERDAHL, C. Maritime Cultural Landscape. In: Oxford Handbook and Maritime Archaeology. CATSAMBIS, A., FORD, B., HAMILTON, D. (ed.). Oxford University Press. New York, 2011a.

WESTERDAHL, C. The maritime cultural landscape. The internacional Journal of Nautical Archaeology. Volume 21. Número 1. 1992. p. 5-14. 